\title{
PREDICTORS OF AND BARRIERS ASSOCIATED WITH HEALTH SERVICES UTILIZATION AMONG PERSONS WITH DISABILITY
}

\author{
Billy Jay N. Pedron \\ De La Salle Medical and Health Sciences Institute, The Philippines
}

\begin{abstract}
In the Philippines, despite numerous initiatives and programs that aims to increase awareness of persons with disability about the different health care benefits intended for them, majority of them still experiences obstacles particularly in accessing health care services. The purpose of the study was to identify predictors and barriers associated to health services utilization among persons with disability. The study used descriptive design, with 77 persons with disability from 3 hospitals in the province of Cavite as respondents. Regression was used to identify the predictors for both health services utilization and barriers. The researcher found out that gender and type of disability has significant differences in terms of health care services utilization, and in terms of experienced barriers, only educational background has significant difference. Further, the study also revealed that age, location and monthly income were significant predictor in utilization of health care services. While, education became significant predictor in predicting barriers in accessing health care services. Different barriers were identified in low level health care services utilization among persons with disability. In this context, strong implementation of policy to increase awareness and knowledge about disability and its prevention in the community level are essential to address the barriers.
\end{abstract}

Keywords: Persons with Disability, Health utilization, Health barriers, Health Systems

\section{Introduction}

Disability is a complex occurrence, which includes a wide array of interaction between features of a person's body and features of the society. Further, it covers a spectrum of various levels of functioning at body level, person level and societal level. (WHO, 2016)

Disability affects hundreds of millions of families in developing countries. Worldwide, it estimated that around $10 \%$ of the total world's population, or roughly 650 million people, live with a disability (WHO, 2010), and about $80 \%$ of the world's population of people with disabilities lives in low-income countries, and most of them experience social and economic disadvantages and denial of rights. Rates of disability are increasing due to population aging and increase in chronic health conditions, among other causes. (WHO, 2010)

Philippines is not spared from this. According to the Asia-Pacific Development Center on Disability the population of persons with disability is estimated at around 942,000 or $1.23 \%$ as to proportion of persons with disabilities to total population. Half of the PWD in the Philippines are old people (60 years and over). The other half are below 49 years old. This could only mean that one in 20 households in the Philippines has at least one member with disability.

In spite of numerous laws and bills passed in the Philippines, people with disability experience different types of barriers when they attempt to access health care. Health systems frequently fail to respond adequately to both the general and specific health care needs of people with disability. Comparing persons with disabilities from the general population, they have both same health care needs. However, they experience unequal access and greater unmet health care needs and experience poorer levels of health compared with the general population. This is mainly due to poverty and social exclusion. People with disabilities in developing countries are over 
represented among the poorest people. Poverty causes disabilities and can further lead to secondary disabilities and complications as a result of the poor living conditions, health endangering employment, malnutrition, poor access to health care and education opportunities, etc. Together, poverty and disability create a vicious circle (World Bank, 2010).

Persons with disability are likely to have limited opportunities to earn income and often have increased medical expenses. Disabilities among children and adults may affect the socioeconomic standing of entire families (American Psychological Association). Poverty, as a contextual factor, may also increase the likelihood, that a health condition may result in impairment, activity limitation, or participation restriction. This could be the case if there is lack of health care and rehabilitation services or lack of resources to access those that are available; acquire prosthetic, orthotic and mobility devices; get personal assistance at the community level, etc. In poor communities where such services are not provided or are of low quality, health conditions may be more likely to lead to disability. Even if such services are available, they may not be affordable (Horner et al. 2003).

Full inclusion of disabled people in society is the solution. To achieve this, we need to remove the barriers that exclude people with disability from participating in society. Health and education should be the primary focus in solving the problem. Health is a prerequisite for it increases in productivity while education relies on adequate health. Both health and education can also be seen as vital components of growth and development. Given their role as both inputs and outputs gives health and education their central importance in economic development (Todaro, 2010).

The purpose of the study was to identify predictors and barriers associated to health services utilization among persons with disability.

\section{Methods}

\section{Study Design and Population}

This study used the quantitative descriptive type of research. This is non-intrusive and deals with naturally occurring phenomena. In this study, the phenomena were the experienced barrier and utilization of health care services of Persons with disability. The participants of the study were the 77 persons with disability who underwent Inclusion criteria and are currently undergoing rehabilitation care under the Level 3 hospitals in Cavite.

\section{Research Instrument}

The research instruments used were self-made questionnaire. Questionnaire were divided into 2 parts: demographics and the barriers and utilization of health care services of PWD. Questions were based on RA 10754 An Act Expanding The Benefits And Privileges Of Persons With Disability (PWD) from RA 7277, as amended, otherwise known as the "Magna Carta for Persons with Disability" and adapted questions from different journals, related literature and studies that discussed barriers and utilization pattern of persons with disability as to health services.

The questionnaire is composed of two parts: the first part sought to obtain the demographic data of the respondents, while the second part includes questions that would determine health care service utilization and barriers.

In determining the barriers that could affect the utilization of health services, the following elements/factors were the bases in formulating questions: a. financial barriers, b. cognitive barrier and c. structural barrier. This part was answered using Likert scale. 5 - very great extent, 4 - great Extent, 3- some extent, 2 - little extent, 1 very little extent. 
Correspondingly, in determining the utilization of respondents, the following health care services were taken into consideration: a. General Health Services b. Dental Services c. Rehabilitative Services d. Psychological Services. his part was answered by a Likert scale. 5 - always, 4 - very often, 3- sometimes, 2 - rarely, 1 - never.

The results were summarized based on the respondents answers on the questionnaire. The mean of the results was obtained for each factor as to the experienced barrier and health care services utilization, and were interpreted using the range below:

Table 1: Arbitrary scale in interpreting Barriers in Healthcare Services

\begin{tabular}{ll}
\hline Barriers in Healthcare Services Scale & \\
\hline Range & Interpretation \\
\hline $5.0-4.50$ & Very Great extent \\
\hline $4.49-3.50$ & Great extent \\
\hline $3.49-2.50$ & Some extent \\
\hline $2.49-1.50$ & Little extent \\
\hline $1.49-1.00$ & Very little extent \\
\hline
\end{tabular}

Table 2: Arbitrary scale in interpreting Utilization of Healthcare Services

\begin{tabular}{ll}
\hline Utilization of Healthcare Services Scale & \\
\hline Range & Interpretation \\
\hline $5.0-4.50$ & Always \\
\hline $4.49-3.50$ & Very Often \\
\hline $3.49-2.50$ & Sometimes \\
\hline $2.49-1.50$ & Rarely \\
\hline $1.49-1.00$ & Never \\
\hline
\end{tabular}

\section{Data Analysis}

Frequency and percentage were used to describe the profile of the respondents in terms of age, gender, type of disability, location, monthly income and education. Weighted mean was employed to determined the experienced barriers and extent of utilization of health care services. Regression Analysis was used to predict the variables that would affect the barriers and utilization of health services.

\section{Result}

\section{Profile of the Respondents}

The profiles of the respondents revealed that out of 77 respondents, majority of which are female (53\%) and belonged to the age bracket of $21-40$ y/o (30\%), who are college level (51\%), from Tagaytay City (30\%), had an average of Php 9,000 per month (49\%), and have orthopedic or mobility disability (70\%). 


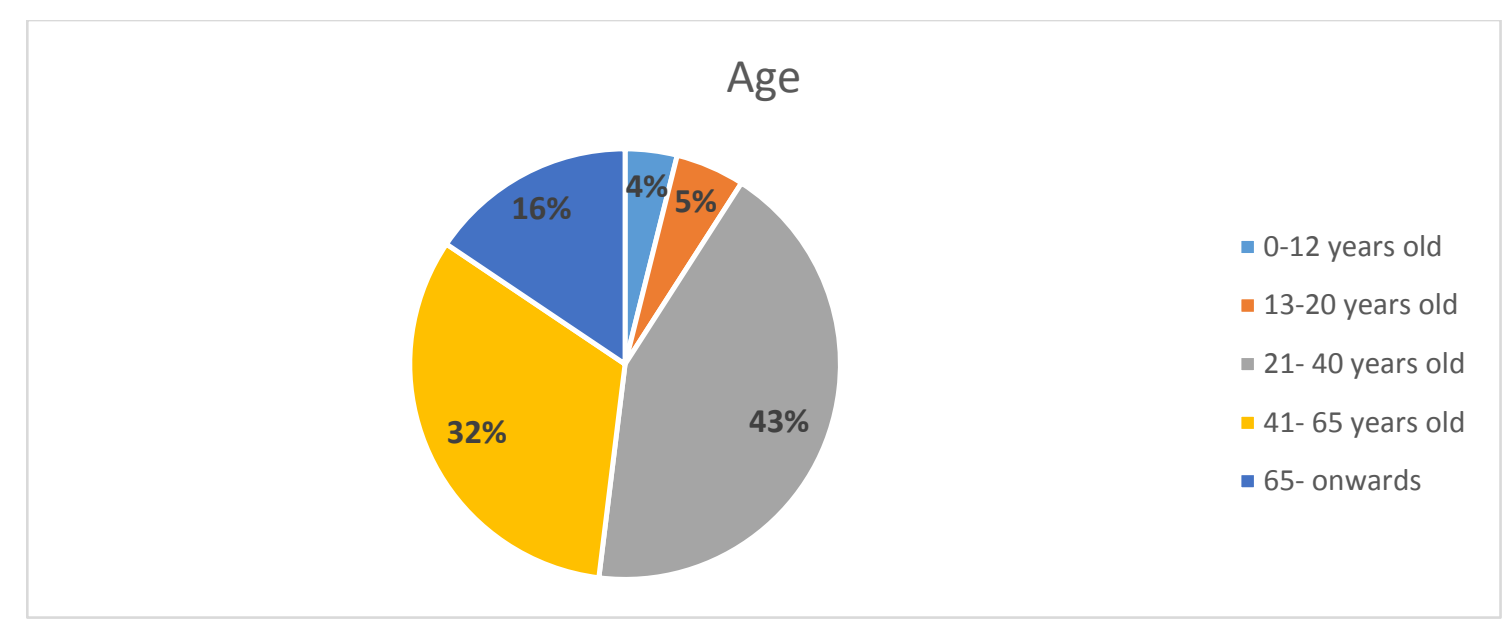

Figure 1: Profile of The Respondents According to Age

Figure 1 shows the profile of the respondents according to age. It revealed that out of 77 respondents, $43 \%$ of the respondents belonged to the age bracket of $21-40 \mathrm{y} / \mathrm{o} ; 32 \%$ were from $41-65 \mathrm{y} / \mathrm{o} ; 16 \%$ from the age bracket of $65 \mathrm{y} / \mathrm{o}-$ on wards; $5 \%$ from $13-20 \mathrm{y} / \mathrm{o}$ and $4 \%$ from 0 - $12 \mathrm{y} / \mathrm{o}$ bracket.

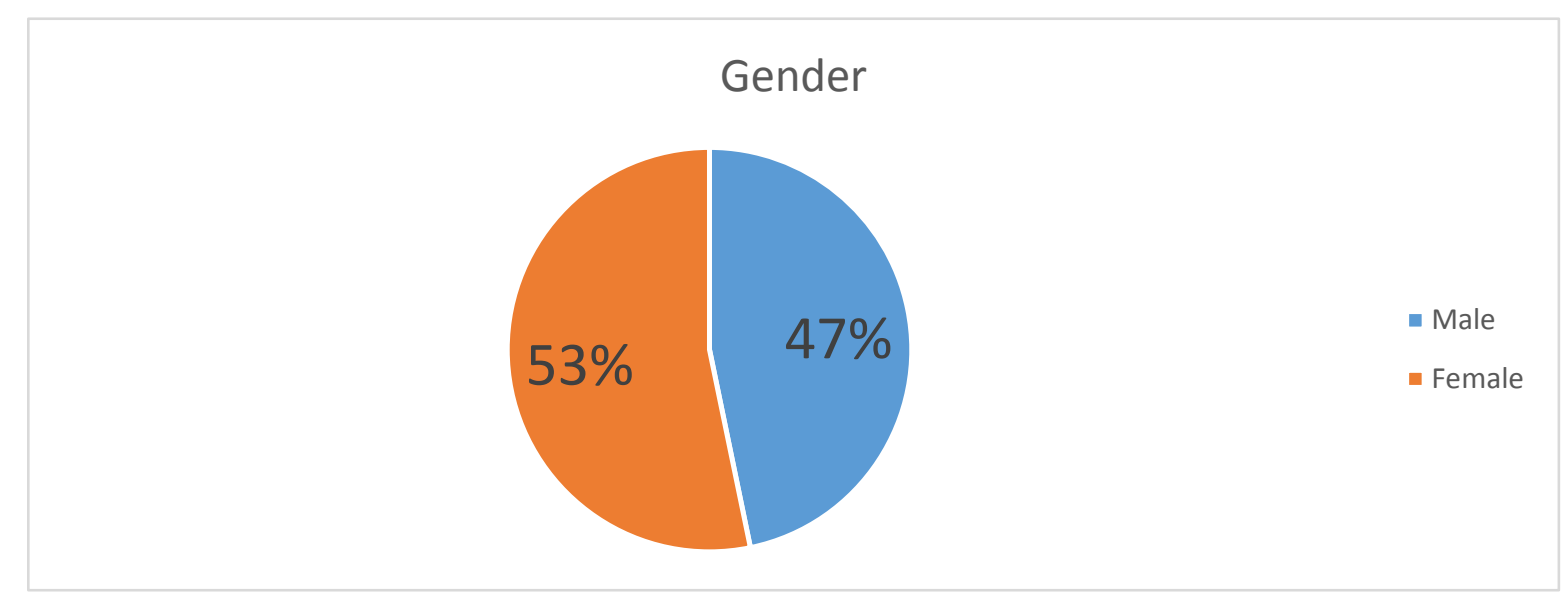

Figure 2: Profile of The Respondents According to Gender

Figure 2 illustrates the profile of the respondents according to gender. The results revealed that out of 77 respondents, $53 \%$ were female and $47 \%$ were male. 


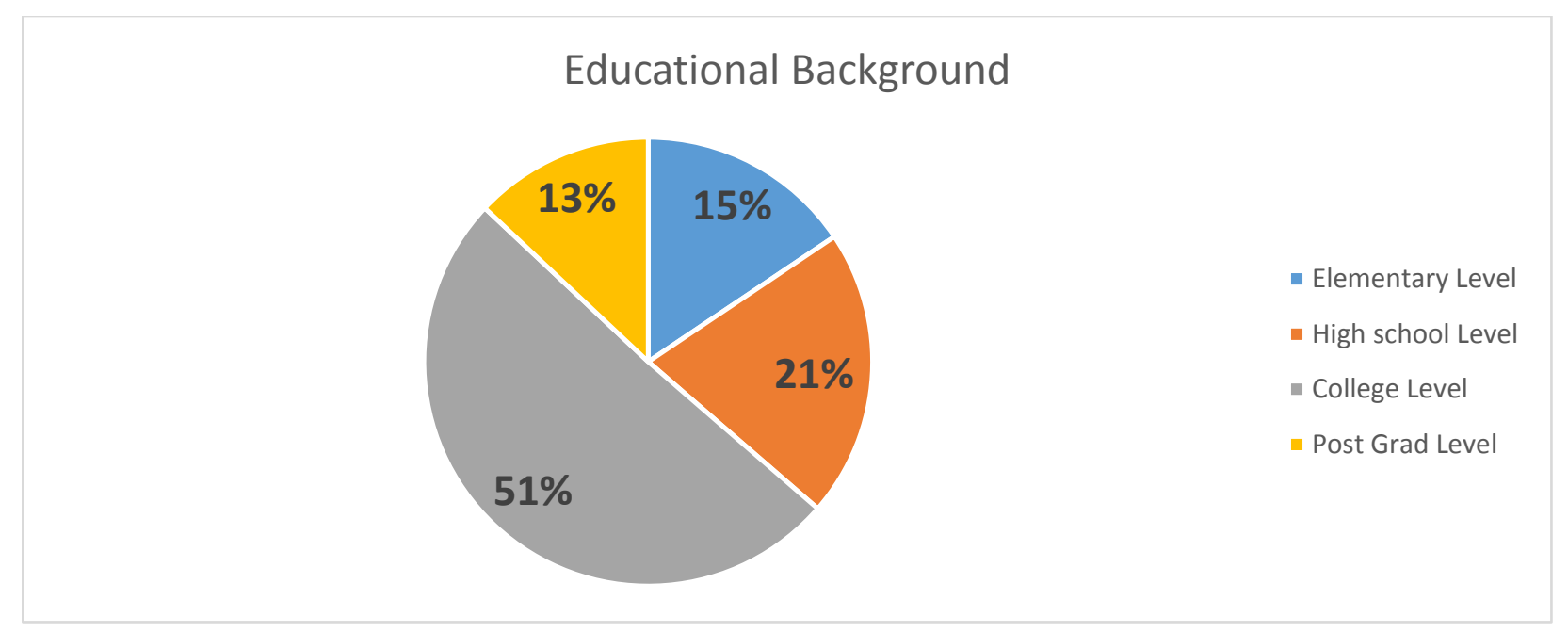

Figure 3: Profile of The Respondents According to Educational Background

Figure 3 revealed that most of the respondents were at the college level (51\%) followed by those at high school level (21\%), then from the elementary level (13\%) and lastly those from the post graduate level (13\%).

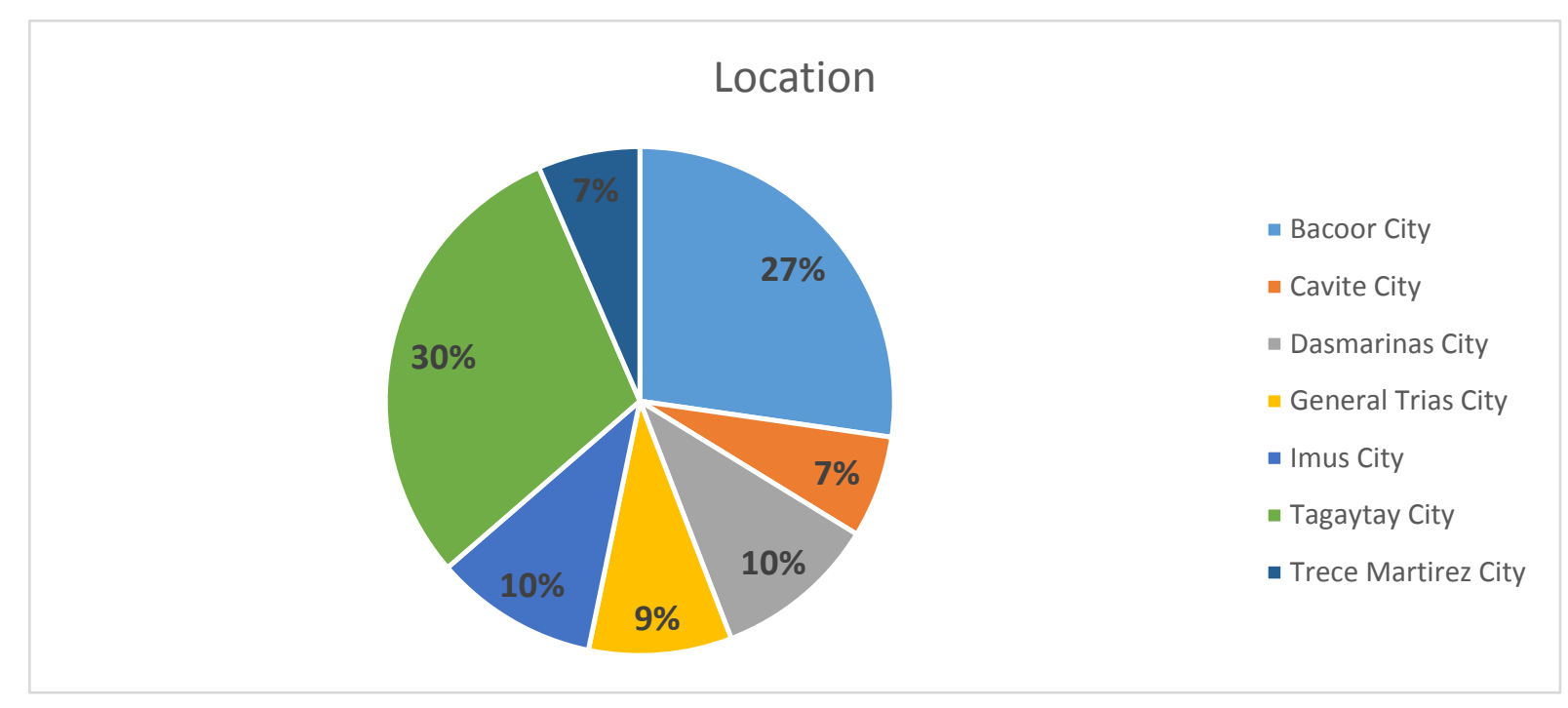

Figure 4: The Profile of the Respondents According to Location

Figure 4 illustrates the profile of the respondents according to location. The results revealed that out of 77 respondents, 30\% were from Tagaytay; 27\% were from Bacoor City; 10\% were from both Dasmarinas City and Imus; $9 \%$ from General Trias and 6\% from both Trece Martirez and Cavite City. 


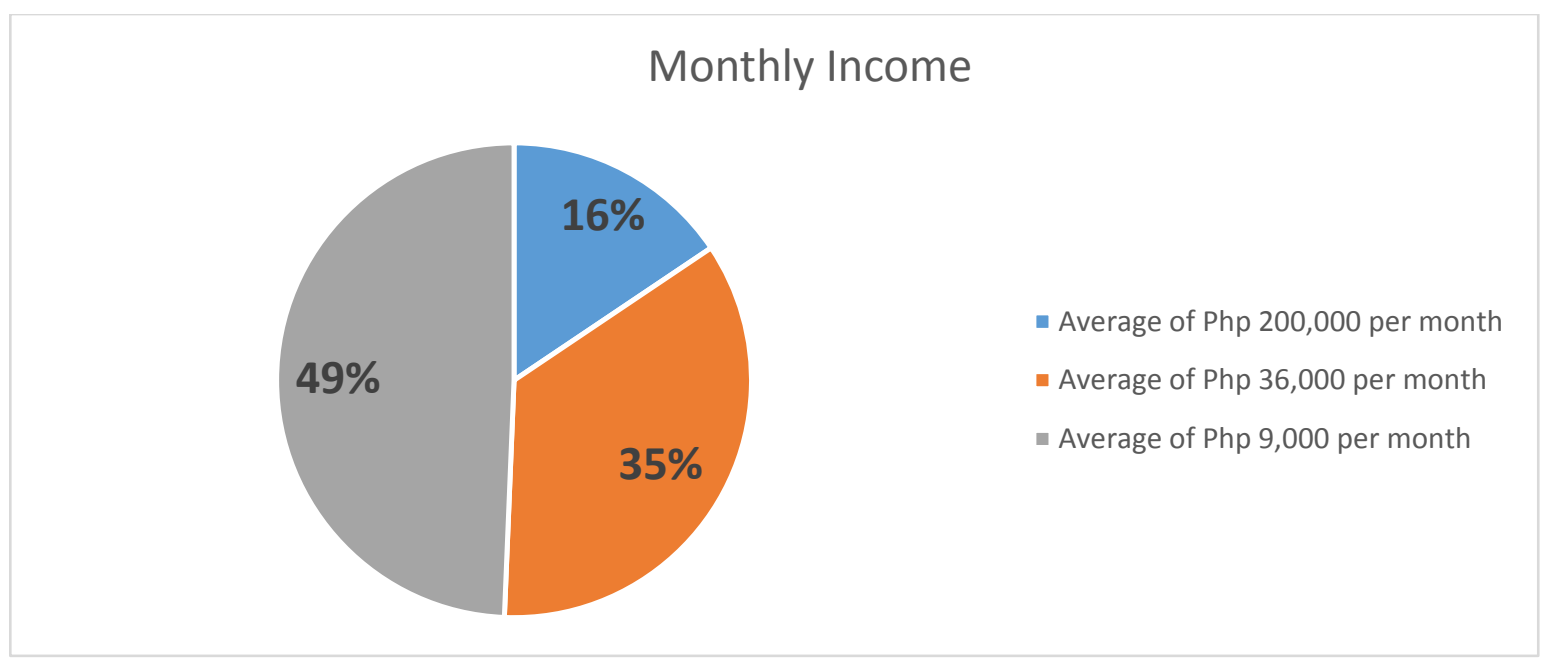

Figure 5: Profile of The Respondents According to Monthly Income

Figure 5 illustrates the profile of the respondents according to monthly income. The results revealed that out of 77 respondents, 49\% has an average of Php 9,000 per month; 35\% has an average of Php 36,000 per month and $16 \%$ has an average of Php 200,000 per month.

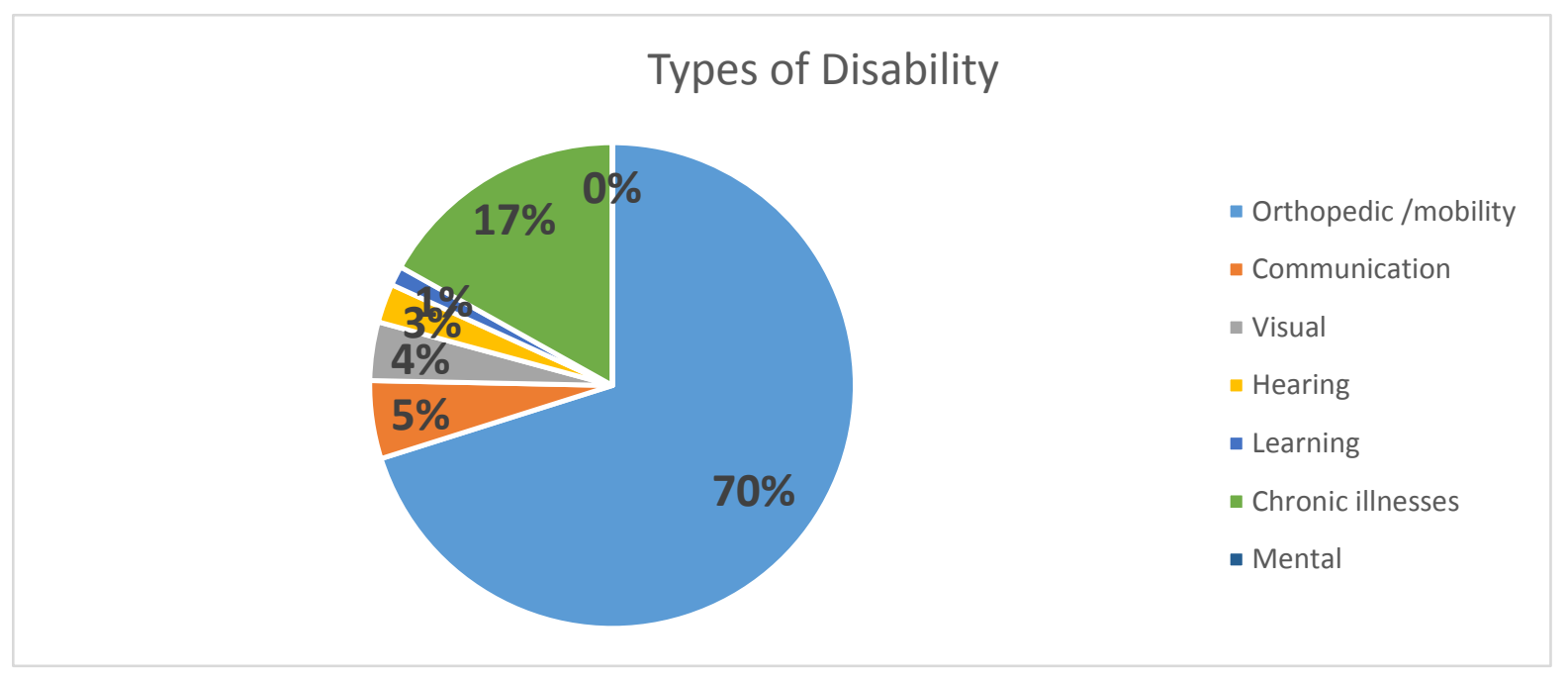

Figure 6: The Profile of the Respondents According to Type of Disability

Figure 6 shows the profile of the respondents according to the type of disability. It revealed that out of 77 respondents, $70 \%$ has orthopedic or mobility disability; $17 \%$ has disability that resulted from chronic illness. $5 \%$ has communication disability; $4 \%$ is visually disabled, $3 \%$ were hearing impaired; $1 \%$ has learning disability, and none has been reported with mental disability.

\section{Predictors of and Barriers Associated with Health Services Utilization}

Respondents experience "some extent" barriers in accessing health care services in terms of financial (over all mean of 2.81), structural (over all men of 2.71) and cognitive (over all mean of 2.6) (Table 3). 
Proceeding of the $4^{\text {th }}$ International Conference on Public Health, Vol. 4, 2018, pp. 1-10

Table 3. Barriers Associated with Health Services Utilization among Persons with Disability

\begin{tabular}{lll}
\hline Type of Barrier & Over all mean & Interpretation \\
\hline Financial & 2.81 & Some extent \\
\hline Structural & 2.71 & Some extent \\
\hline Cognitive & 2.6 & Some extent \\
\hline
\end{tabular}

Meanwhile, based on the evaluation of health care services utilization, general health/ medical services are "sometimes" utilized (over all mean of 2.67) while, rehabilitative (over all mean of 2.25), dental (2.10) and psychological (1.55) are "rarely" utilized by the respondents (Table 4).

Table 4. Utilization of Healthcare Services among Persons with Disability

\begin{tabular}{lll}
\hline Healthcare Services & Over all mean & Interpretation \\
\hline General Health/ Medical Services & 2.67 & Sometimes \\
\hline Rehabilitative & 2.25 & Sometimes \\
\hline Dental & 2.10 & Sometimes \\
\hline Psychological & 1.55 & Rarely \\
\hline
\end{tabular}

Based on the results of regression analysis for variables predicting health services utilization among persons with disability, age, location and monthly income are significant predictors of utilization of health care with $\mathrm{p}$ value less than 0.05 (Table 5).

Table 5: Regression analysis for variables predicting health services utilization

\begin{tabular}{|c|c|c|c|c|c|}
\hline$\beta \mathrm{j}$ & t-statistics & Ho & $\mathrm{Ha}$ & p-value & Conclusion \\
\hline Age & 2.04 & $\beta 1=0$ & $\beta 1 \neq 0$ & 0.045 & Reject Ho \\
\hline Gender & -0.52 & $\beta 2=0$ & $\beta 2 \neq 0$ & 0.606 & Accepted \\
\hline $\begin{array}{l}\text { Type of } \\
\text { Disability }\end{array}$ & -0.61 & $\beta 3=0$ & $\beta 3 \neq 0$ & 0.547 & Accepted \\
\hline Location & 2.30 & $\beta 4=0$ & $\beta 4 \neq 0$ & 0.025 & Reject Ho \\
\hline $\begin{array}{l}\text { Monthly } \\
\text { Income }\end{array}$ & -4.37 & $\beta 5=0$ & $\beta 5 \neq 0$ & $<0.001$ & Reject Ho \\
\hline $\begin{array}{l}\text { Educational } \\
\text { Background }\end{array}$ & 0.07 & $\mathrm{~B} 6=0$ & $\mathrm{~B} 6 \neq 0$ & 0.941 & Accepted \\
\hline$F$ - statistics: & $p$-value & $O 2 R M$ & 48829 & quared & 3113 \\
\hline
\end{tabular}

Based on the table above, using F-statistics, it can be concluded that at least one of the independent variables is a good predictor of utilization of health services. The $31.13 \%$ variability of utilization of health services can be accounted from the given independent (predictor) variables. Furthermore, based on t-statistics, only age, location and monthly income become statistically significant predictor of utilization of health care with p-value less than 0.05. Low RMSE value of 0.48829 indicates a well-fitting

Further, the results of regression analysis for variables predicting barriers in accessing health services among persons with disability only education is statistically significant predictor of utilization of health care with $\mathrm{p}$ value less than 0.05 . 
Table 6: Regression analysis for variables predicting barriers in accessing health services utilization

\begin{tabular}{llllll}
\hline$\beta \mathrm{j}$ & $\mathrm{t}$-statistics & Ho & $\mathrm{Ha}$ & $\mathrm{p}$-value & Conclusion \\
\hline Age & $-0,01$ & $\beta 1=0$ & $\beta 1 \neq 0$ & 0.992 & Accepted \\
\hline Gender & 0.78 & $\beta 2=0$ & $\beta 2 \neq 0$ & 0.436 & Accepted \\
\hline Disability & -0.83 & $\beta 3=0$ & $\beta 3 \neq 0$ & 0.412 & Accepted \\
\hline Location & 0.82 & $\beta 4=0$ & $\beta 4 \neq 0$ & 0.415 & Accepted \\
\hline Mi & 0.75 & $\beta 5=0$ & $\beta 5 \neq 0$ & 0.459 & Accepted \\
\hline Educ & -5.83 & $\mathrm{~B} 6=0$ & $\mathrm{~B} 6 \neq 0$ & $<0.001$ & Reject Ho \\
\hline F- statistics: & $6.71 p$-value: $<0.0001$ & RMSE: 0.72166 R-squared: 0.3652
\end{tabular}

Based on table shown, it can be concluded that at least one of the independent variables is a good predictor of the perceived barriers experienced by the respondents. The $36.52 \%$ variability of utilization perceived barriers experienced by the respondents can be accounted from the given independent (predictor) variables. Furthermore, based on t-statistics, only education become statistically significant predictor of the perceived barriers experienced by the respondents with p-value less than 0.05 .

\section{Discussion}

Respondents experienced "some extent" financial barriers in accessing health care services. In low-income countries (LIC), health care and related expenditures feature prominently as causes of impoverishment. Moreover, Krishna (2006) identified the cost of treatment for illness to be the cause of $85 \%$ of all cases of impoverishment. Van Doorslaer et al. (2006) found that an additional 78 million people in 11 Asian countries fall below the extreme. One cause of low patient compliance to physical therapy is financial difficulty. Low compliance to therapy can prolong the recovery of the patient; thus, increasing the difficulty for both patient and family. Both the patient and the family experience the financial difficulty brought about by poverty. With regard to structural barriers, respondents experienced "some extent" difficulty in accessing health care services. The noted difficulty are coming from the distance of the health care facilities, transportation and the process in availing health care services and lack of initiatives coming from the government. PWD and providers both perceive transportation issues as the highest ranked barriers and physical access issues as the lowest ranked barriers (Mc Doom et. al, 2014). Further, PWD find it difficult to walk to health centers for treatment due to lack of transport, money to pay for treatment and toilet facilities and the distance is too far for people with lower-limb disabilities. There is a need to consider the different issues affecting health care access for people living with disabilities to achieve equitable access to health care services (Van Rooy, 2012). Equally, respondents generally experience "some extent" difficulty in accessing health care services due to cognitive barriers. Respondents experience barriers in availing government services, and have limited knowledge as to the law and provisions and the different services being offered to the persons with disability. This revealed an agreement with Chopra (2013), where he expressed that lack of information regarding governmental schemes and policies in favor of disabled people is another major barrier faced by them. In addition, People with disabilities also had trouble accessing health care facilities and services in part due to lack of access to adequate rehabilitation devices and services. In the case of people who are deaf or have difficulty of hearing, they have difficulties communicating with health care professionals and getting emergency services. According to WHO (2016), policy barriers are frequently related to a lack of awareness or enforcement of existing laws and regulations that require programs and activities be accessible to people with disabilities. Given these findings, we can infer that PWDs still experience difficulty in availing health care services due to limited knowledge. Limited knowledge of PWDs can affect the implementation of the program of the government in addressing the problems and the needs of PWDs. Government should focus in strengthening its information campaign drive in reaching PWD not only in the city but also in the far flung areas. 
On health care services utilization, majority of the general health and medical services are utilized by PWD; services such as checkup, laboratory examination and vaccination are "sometimes" utilized. Regular checkup and laboratory examination can help prevent problems or secondary complication. Checkups can detect early problems that can be treated by conservative management. Moreover, vaccination is important not only for children with disability but also for adult and geriatric patients. Vaccination has greatly reduced the burden of infectious diseases. Further, benefits of vaccination extend beyond prevention of specific diseases in individuals. Conversely, Referrals to other health professionals, health education, nutritional counseling as well as surgical procedure are "rarely" utilized. Referral is considered an important part of patient care especially to the PWD. PWD should be referred to other specialist for further management, treatment or as needed. Dental services such as routine checkups, dental prophylaxis, laboratory and diagnostics examination are "rarely" utilized by PWD. According to National Institute of Dental Craniofacial Research, smaller-scale studies show that the population with mental retardation or other developmental disabilities has significantly higher rates of poor oral hygiene and needs periodontal disease treatment than the general population, due, in part, to the limitations in individual understanding of and physical ability to perform personal prevention practices or to obtain needed services. In the aspect of Rehabilitative Services, checkups, follow ups and physical therapy services are "sometimes" utilized by the respondents. Rehabilitation of persons with disability reduces the impact of a broad range of health conditions. Typically, rehabilitation occurs for a specific period of time, but can involve single or multiple interventions delivered by an individual or a team of rehabilitation workers, and can be needed from the acute or initial phase immediately following recognition of a health condition through to post-acute and maintenance phases. Rehabilitation involves identification of a person's problems and needs, relating the problems to relevant factors of the person and the environment, defining rehabilitation goals, planning and implementing the measures, and assessing the effects. Educating people with disabilities is essential for developing knowledge and skills for self-help, care, management, and decision-making. People with disabilities and their families experience better health and functioning when they are partners in rehabilitation. Therapy is important for immediate recovery after the injury so as to prevent disability. Early rehabilitation interventions seem to be essential for how well a patient recover after a severe brain injury. It might even increase the chances for long-term survival. Likewise, Convincing evidence shows that some therapy measures improve rehabilitation outcomes. Therapy interventions have also been found to be suitable for the long-term care of older persons to reduce disability. Some studies show that training in activities of daily living have positive outcomes for people with stroke. Based on the researcher's experience, patients compliance to treatment is also affected by the the cost of the therapy, chronic illness and disability usually have a greater financial impact to the patient and to the family.

Based on the regression model and the inter relationship of the variables (contextual factors, barriers and the health care services utilization) among persons with disability, only few variables in the respondents demographics can be used as predictors in both health utilization and barrier. Identifying the needs of the respondents and increasing its health literacy through health education can directly affect the utilization. In the same token, identifying the barriers and finding solutions to address those problems can greatly affect the health care services that can also affect the utilization. Increase in health care services utilization leads to inclusive health care services.

\section{Conclusion}

Generally, persons with disability are still considered part of the vulnerable sector in the country, and rates of disability were increasing due to population aging and increases in chronic health conditions, among other causes. In spite of numerous bills and law that are geared towards inclusive society, PWD still face barriers in everyday activities which have greater impact in their lives particularly on their health. As identified in research literature, people with disabilities have less access to health care services and therefore experience unmet health care needs. Like ordinary individuals, they have general health care needs and therefore need access to mainstream health care services. However, within these constraints, the study has provided much needed 
information on socio economic determinants differences of PWD populations by describing differences in experienced barriers and health care services utilization. At present, health care service development is based on the assumption that service provision reflects assessed need. It is therefore suggested that these barrier and utilization data be used to inform the development of planning, particularly for PWD, where planners often lack information about the characteristics and service used of their shared care populations.

\section{Recommendation}

Identify the persons with disability in the community and develop an up-to-date databank for easy identification of the PWDs.

Create a Barrier-free environment advocacy or initiatives the enables people with disabilities to perform independent functioning as an individual so that they can participate without assistance in everyday activities.

Develop Disability Prevention Policy - Disability can be prevented through proper education. Strong policy that will focus on disease prevention that can result to disabilities. Further, this involves creation of awareness regarding measures to be taken for the prevention of disabilities during the different stages of pregnancy and other work related injuries.

\section{References}

Chopra, T. (2013). Expanding the horizons of disability law in India: a study from a human rights perspective. The Journal Of Law, Medicine \& Ethics: A Journal Of The American Society Of Law, Medicine \& Ethics, 41(4), 807. doi:10.1111/jlme.12091

Horner-Johnson, W., Dobbertin, K., Lee, J. C., \& Andresen, E. M. (2014). Disparities in health care access and receipt of preventive services by disability type: analysis of the medical expenditure panel survey. Health Services Research, $\quad$ 49(6), 1980-1999. doi:10.1111/1475-6773.12195

Krishna A. Pathways out of and into poverty in 36 villages in Andhra Pradesh, India, World Development , 2006, vol. 34 (pg. 271-88)

Mcdoom, M. Maya \& Koppelman, Elisa \& Drainoni, Mari-Lynn. (2012). Barriers to Accessible Health Care for Medicaid Eligible People With Disabilities: A Comparative Analysis. Journal of Disability Policy Studies. 25. $10.1177 / 1044207312469829$.

Todaro, M. P., \& Smith, S. C. (2009). Economic development. Boston: Pearson Addison Wesley.

Van Doorslaer E, O’Donnell O, Rannan-Eliya R, et al. Effect of payments for health care on poverty estimates in 11 countries in Asia: an analysis of household survey data, The Lancet, 2006, vol. 368 (pg. 1357-64)

Van Rooy, G., Amadhila, E. M., Mufune, P., Swartz, L., Mannan, H., \& MacLachlan, ～M. (2012). Perceived barriers to accessing health services among people with disabilities in rural northern Namibia. Disability \& Society, 27(6), 761- 775 15p. doi:10.1080/09687599.2012.686877

World Health Organization (2016) Disability and Rehabilitation . Retrieved from http://www.who.int/disabilities/en/

World Bank (2016) Disability. Retrieved from

http://www.worldbank.org/en/topic/disability 